\title{
NECESIDADES HUMANAS Y DERECHOS ABSOLUTOS. UNA PAREJA INESTABLE
}

\author{
Eusebio Fernández García \\ Universidad Carlos III de Madrid
}

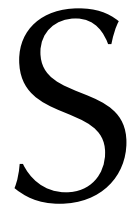

i deseamos hoy hacer una rápida descripción de las cuestiones que ocupan el trabajo teórico de los filósofos del derecho y de los filósofos de la política es fácil reparar que una de ellas tiene que ver con el concepto y el fundamento de los derechos humanos. Y, de la misma manera, una teoría de los derechos humanos aparece como una candidata especial para convertirse en una teoría de la justicia. Que esto sea así no significa que los problemas filosóficos en torno a la idea de que los seres humanos, por el hecho de serlo, tienen una serie de derechos fundamentales, básicos e imprescindibles, que deben ser reconocidos por el poder político, el ordenamiento jurídico y, en general, la comunidad propia y la sociedad internacional, hayan sido ya solucionados y gocen de una vida pacífica. No obstante, los desacuerdos ideológicos, políticos y teóricos son inferiores al acuerdo social producido por el impacto que crea la referencia a la defensa o a la violación de los derechos humanos. Lo que quiere decir que, al menos intuitivamente, nos sentimos bastante próximos a reconocer el contenido y el alcance de una declaración universal de derechos humanos. Y ya existe una: la de la ONU de 1948.

Mientras los desacuerdos ideológicos pueden girar en torno a «qué derechos humanos tenemos» y «qué prioridades se dan entre ellos» (única forma de solucionar los conflictos que plantea su ejercicio), los desacuerdos teóricos suelen responder a las preguntas sobre «cómo fundamentarlos»o «qué significa tener un derecho». Conviene no olvidar, al respecto, que la frontera entre los desacuerdos ideológicos y los desacuerdos teóricos no está totalmente cerrada.

Tampoco debemos dejar de tener en cuenta que la existencia de desacuerdos teóricos en torno a los derechos humanos no tiene por qué interpretarse como un dato negativo. Todo lo contrario. Significa que el concepto en cuestión es objeto de discusión y debate. Y que la argumentación racional ha sustituido a la simple creencia y a su invocación emotiva. La bibliografía existente en cualquier biblioteca universitaria de nuestro entorno es enorme. Alguna vez se ha señalado que los derechos humanos son el tema de nuestro tiempo o que nos encontramos en la edad de los derechos, y lo cierto es que, además, este fenómeno ha enraizado, también, en el trabajo académico, hasta lograr, a veces, un nivel de sofisticación importante. Creo que los trabajos sobre derechos humanos, elaborados y publicados por Liborio HIERRO y Francisco LAPORTA, y sobre los que (una mínima selección de ellos) voy a sustentar las opiniones que 
siguen, son una buena prueba de que el nivel teórico alcanzado en nuestra comunidad es alto. Conviene hacer la advertencia de que es difícil evitar que alguien nos objete que esa señal de mejora teórica es insuficiente, e incluso que puede tener un efecto paralizador (y, yendo más allá en la crítica, cómplice) frente a la cruda realidad de la violación de los derechos humanos más básicos, desde la merma en la representación democrática, a la situación de los refugiados o el aumento de las desigualdades económicas. Dada la singularidad y la complejidad de la «vocación» práctica de los derechos humanos es conveniente hacerse a la idea de que hay que estar preparados ante la opinión crítica de que la tarea prioritaria en derechos humanos (una vez que se cuenta con el consenso suficiente expresado en la Declaración de 1948) es garantizarlos. Pues bien, esta versión simplificada de la tesis (exagerada) sustentada por N. BOBBIO, en los años sesenta del pasado siglo, en torno al fundamento de los derechos humanos se basa en dos supuestos falsos: 1) que la invocación a la Declaración Universal de Derechos Humanos sea la respuesta suficiente a los problemas teóricos de la fundamentación de los derechos humanos, y 2) que esta respuesta sea la solución definitiva. Los trabajos de Liborio HIERRO y Francisco LAPORTA sobre los derechos humanos (los aquí citados y los demás) vienen en ayuda de la tesis de la necesidad y pertinencia de plantearse las cuestiones relativas al concepto y al fundamento de los derechos humanos. Y su aportación es muy relevante.

Y una tercera idea que sirve, además, para apuntalar la tesis de que también una buena fundamentación de los derechos ayuda a establecer mejores garantías para su ejercicio: ninguno de los dos profesores ha olvidado nunca el ámbito práctico de los derechos humanos: ni en sus trabajos académicos, ni en sus cargos institucionales ni en la vida cotidiana.

Hasta aquí he mencionado tres características que comparten Liborio HIERRO y Francisco LAPORTA. Recordemos: su notable aportación al estudio de los derechos humanos, su interés especial por el asunto del concepto y el fundamento de los derechos humanos y su no olvido de los aspectos prácticos que conllevan los derechos humanos, tanto los relativos a su reconocimiento y garantías en el marco del Estado de Derecho (imperio de la ley, tema bien estudiado por ambos) y de un régimen de democracia liberal y constitucional (abierto a los postulados de un socialismo liberal y democrático) como los que tienen que ver con el ejercicio de los derechos humanos en la conducta diaria y en las elecciones y decisiones del ciudadano corriente.

A partir de ahora, deseo referirme a los puntos en los que creo que existen desacuerdos, más o menos significativos, entre ambos. El primero de ellos se dirige directamente al núcleo de la idea de tener un derecho o concepto de derecho humano. Valdría tanto para el ámbito moral como para el ámbito jurídico, aunque me interesa más el segundo. Las razones son dos: primera, porque, aunque el concepto de derechos humanos pertenece a los conceptos morales, su desarrollo completo precisa de su extensión al campo político y jurídico (reconocimiento jurídico, es decir, positivación y creación de garantías jurídicas para su normal ejercicio); segunda, porque en el fundamento o justificación de una norma jurídica receptora de un derecho siempre se encuentra un valor moral ( $v$. gr. seguridad, libertad, igualdad), es decir, toda fundamentación de los derechos humanos es una fundamentación ética. 
En un trabajo de Liborio HIERRO, relativamente temprano en cuanto a su producción intelectual y pionero, entre nosotros, en cuanto al tema objeto de estudio, titulado «¿Derechos humanos o necesidades humanas? Problemas de un concepto», publicado en el núm. 46 de la revista Sistema (enero de 1982) nos encontramos con dos ideas que sirven para analizar el concepto y el alcance moral y jurídico de los derechos humanos y que, salvo error mío, se mantienen hasta la actualidad. Se trata de la relación entre derechos humanos y necesidades humanas y de la correspondiente al nexo entre derechos humanos y deberes morales y jurídicos. En el primer caso, mantendrá la tesis de que «tener un derecho es tener una necesidad cuya satisfacción hay razones suficientes para exigir en todo caso; consecuentemente, tener un derecho es, jurídicamente hablando, tener una necesidad que las normas del sistema jurídico exigen satisfacer en todo caso» (p. 57). En el segundo supuesto, nos encontramos ante el requisito de que existan medios para satisfacer la necesidad requerida por el derecho y, en ese caso, se podría cumplir la exigencia de que los derechos sirvan para justificar los deberes. El nexo derechos-deberes quedaría planteado así: «Solo podemos sostener como derechos aquellas necesidades humanas que exigen su satisfacción de forma incondicional, cual si se tratara de un fin en sí mismo, y solo cuando existan posibilidades de satisfacerlas, cuando podamos imponer sobre otros los correlativos deberes según sus posibilidades» (p. 61).

De lo resumido y expuesto anteriormente podemos derivar dos conclusiones. Primera: un concepto de derechos humanos que contiene las ideas de necesidades humanas a satisfacer, los valores morales que los fundamentan y los deberes jurídicos a imponer para su realización. Segunda: la tesis de que tenemos tantos derechos humanos básicos o fundamentales como necesidades humanas a satisfacer de manera inexcusable. De todas maneras, falta en Liborio HIERRO una teoría explicativa de cómo se pasa de las necesidades humanas inexcusables a los valores fundamentadores de los derechos humanos: libertad, igualdad y seguridad.

En el núm. 4 de la revista Doxa (Alicante, 1987) aparece un artículo de Francisco LAPORTA titulado «Sobre el concepto de derechos humanos», que había constituido la ponencia presentada por él en las X Jornadas de la Sociedad Española de Filosofía Jurídica y Social, celebradas en Alicante en diciembre de 1987. En ella se trata sobre todo de analizar tres características que irían conectadas a la idea de «tener un derecho...», o «que se suelen adscribir a ellos en el lenguaje ético, jurídico y político». La primera es la universalidad, la segunda señala el carácter de «absolutos», referida a su importancia o a que contienen una «exigencia moral fuerte», la tercera añadiría el carácter de inalienables o no renunciables.

Por razones de espacio no puedo entrar en la argumentación de F. LAPORTA y en las posibles matizaciones que cabría hacer. Me parece que no hay un desacuerdo básico con el concepto de derechos humanos antes señalado. Pues tanto Liborio HiERro como Francisco LAPORTA coincidirían en la idea de la importancia fundamental que adquieren los derechos humanos en el ámbito moral, político y jurídico. Tan básicos que sería difícil hoy pensar en una sociedad buena, decente o justa sin garantizar esas exigencias derivadas de reconocer a los seres humanos su dignidad y autonomía. Lo que no estoy seguro es de que Liborio HIERRO pueda aceptar, sin añadidos o matices, el sentido literal del carácter absoluto de los derechos humanos. Quizá se lo impida 
la conexión exigida y propiciada por él entre las necesidades humanas y los derechos humanos. Y teniendo en cuenta que las necesidades humanas, salvo las propias de la especie, tienen mucho de cultural e histórico, es difícil buscar derechos absolutos en un campo tan minado de relativismo histórico (no necesariamente relativismo moral).

Tampoco Liborio HIERRO admite, y esto de manera explícita, como se indicará más tarde, una tesis que F. LAPORTA defiende en su trabajo: que «ampliar más y más los catálogos de derechos humanos es incompatible con la mayoría de los rasgos que se predican de ellos» (p. 44).

Esos rasgos de los derechos humanos son mantenidos y revalorizados en un trabajo posterior de F. LAPORTA que aparece en el tercer tomo de la Historia de la Ética (3. La Ética contemporánea, Barcelona, Crítica, 1989), editada por V. CAMPS, con el título «Ética y derecho en el pensamiento contemporáneo». Allí se presentan los derechos humanos como derechos «básicos» y «derechos morales anteriores al sistema de normas jurídicas», al que dan legitimidad o justificación (p. 292). Y esos derechos cuentan con los tres rasgos que les confieren «una especial fuerza moral»: se trata de derechos universales, absolutos e inalienables. Pero a Francisco LAPORTA no se le esca$\mathrm{pa}$, y nos lo recuerda, el dato de que al adornar el concepto de derechos humanos de rasgos tan importantes, exigentes y fuertes, «no parece que pueda afirmarse fácilmente que son tan numerosos y complejos como dan a entender los catálogos internacionales y constitucionales al uso. Más bien habría que pensar en dos o tres derechos básicos, a partir de los cuales se derivarían derechos constitucionales más específicos en función de los contextos sociales y las circunstancias históricas» (p. 293). Al leer este párrafo cabe preguntarse si los dos o tres derechos básicos permanecen ajenos o están por encima de los contextos sociales y las circunstancias históricas. Pregunta que difícilmente se puede responder ya que (salvo error de conocimiento mío) F. LAPORTA nunca ha indicado cuáles son esos dos o tres derechos básicos. Quizá la lectura de su libro sobre «El imperativo de la ley» nos permita concluir que está pensando, al menos, en la autonomía.

Posteriormente en un capítulo [el primero «El concepto de justicia y la teoría de los derechos» del libro «Estado, justicia, derechos», Elías DíAZ y José Luis COLOMER (eds.), Alianza Editorial, 2002] Liborio HIERRO explicita dos desacuerdos con la teoría de los derechos humanos de F. LAPORTA, que me parecen dignos de señalar. El primero es una crítica a su idea reflejada al comienzo y al final del trabajo «Sobre el concepto de derechos humanos». Con sus palabras: «Cuanto más se multiplique la nómina de los derechos humanos menos fuerza tendrán como exigencia, y cuanto más fuerza moral o jurídica se les suponga más limitada ha de ser la lista de derechos que la justifiquen adecuadamente» (p. 23). A esta postura Liborio HIERRO la denomina «prejuicio elitista que diría algo así como si son pocos, son mejores» (pp. 37 y 64). Estoy del lado de los reparos y cuidados de F. LAPORTA por las mismas razones que él expresa en el texto anterior y que no voy a repetir. Simplemente añadir que cada vez nos encontramos más la situación en la que cualquier reivindicación social de interés se quiere vestir de derecho humano fundamental y ello suele tener como consecuencia que se debilita la fuerza de la reivindicación de los que son auténticos derechos humanos fundamentales. El trabajo de Liborio HIERRO «El concepto de justicia y la teoría de los derechos» nos aporta pistas para poder distinguir entre las reivindicaciones interesadas, oportunistas y par- 
ciales y los derechos humanos (y también para descubrir un segundo desacuerdo entre ellos). Una vez más la inclusión de la idea de necesidades humanas imprescindibles, fundamentales o básicas es aquí muy oportuna a la hora de establecer la nómina de los derechos morales básicos, llamados a convertirse en derechos humanos fundamentales, y no cerrarla, como si fuera intemporal. Pues habría que tener en cuenta siempre que las «necesidades del sujeto para desenvolverse como agente moral son necesidades relativas al contexto» (p. 50).

Es decir, sería beneficioso para la teoría o filosofía de los derechos humanos que tomemos en consideración algo parecido a lo que en filosofía de la ciencia se viene denominando el contexto de descubrimiento, aunque tuviéramos que aparcar algunas sutilezas y sofisticaciones tan caras a algunos filósofos analíticos que no se parecen a Liborio HIERRO y Francisco LAPORTA (aunque, por decirlo demasiado rápidamente, todos deberíamos ser, desde el punto de vista metodológico, bastante analíticos). 